Cahiers $d u$ MONDE RUSSE

\section{Cahiers du monde russe}

Russie - Empire russe - Union soviétique et États indépendants

$49 / 4 \mid 2008$

Destins individuels et terreur. Jeunesse dans la société post-stalinienne

\title{
Sophie Cœuré, Sabine Dullin, éds, Frontières du communisme
}

Juliette Denis

\section{OpenEdition}

\section{Journals}

Édition électronique

URL : https://journals.openedition.org/monderusse/7027

DOI : 10.4000/monderusse. 7027

ISSN : $1777-5388$

Éditeur

Éditions de l'EHESS

\section{Édition imprimée}

Date de publication : 28 décembre 2008

Pagination : 851-854

ISBN : 978-2-7132-2197-2

ISSN : $1252-6576$

Référence électronique

Juliette Denis, "Sophie Cœuré, Sabine Dullin, éds, Frontières du communisme », Cahiers du monde russe [En ligne], 49/4 | 2008, mis en ligne le 24 décembre 2009, consulté le 03 septembre 2022. URL http://journals.openedition.org/monderusse/7027 ; DOI : https://doi.org/10.4000/monderusse.7027

Ce document a été généré automatiquement le 3 septembre 2022

Tous droits réservés 


\title{
Sophie Cœuré, Sabine Dullin, éds, Frontières du communisme
}

\author{
Juliette Denis
}

\section{RÉFÉRENCE}

Sophie CÆURÉ, Sabine DULLIN, éds, Frontières du communisme. Paris : La Découverte, 2007, 458 p. (collection « Recherches »).

1 Le travail collectif dirigé par Sophie Cœuré et Sabin Dullin, qui rassemble les actes d'un colloque qui s'est déroulé à Paris (Université Paris I-Panthéon-Sorbonne/École normale supérieure de la rue d'Ulm) du 18 au 20 mai 2006, s'insère dans un programme de recherches sur la frontière communiste de 1917 à l'érection du mur de Berlin en 1961. Comme les deux coéditrices le rappellent en introduction, l'objectif principal est de cerner la spécificité de la division du territoire européen, en interrogeant tout aussi bien les pratiques que les représentations de ces frontières. L'un des grands intérêts de l'ouvrage est d'avoir confronté des études sur la frontière telle qu'elle est vécue et perçue au sein de l'URSS et des démocraties populaires avec d'autres qui portent sur le monde occidental. Au-delà de la dimension comparative, il s'agit bien d'une volonté de questionner l'ampleur européenne d'un même phénomène - celui de la séparation engendrée par la révolution bolchevique et des réactions qu'elle a suscitées, au long des multiples modifications de frontières des années1920 aux années 1950.

Quelle est la place de la frontière dans le développement et l'imaginaire du communisme après 1917 ? En Russie bolchevique, l'« utopie de non-frontière », selon l'expression de Jean-Baptiste Duroselle (cité p. 10), consubstantielle à l'appel à la révolution mondiale, cède rapidement la place à la défense de la "patrie du prolétariat ", encerclée par les pays capitalistes. Cette évolution est visible dans l'iconographie soviétique, analysée par Christophe Barthélémy à travers les affiches de propagande. Le régime prend de plus en plus conscience de ses frontières, qui deviennent des enjeux de taille dans les relations avec ses proches voisins mais également entre le centre et sa périphérie. Le garde- 
frontière accompagné de son chien (dont l'une des représentations les plus connues est la statue érigée à la station de métro moscovite Place de la Révolution) symbolise cette «frontière verrouillée». Parmi les différents " héros soviétiques" présentés comme modèles aux enfants, le garde-frontière occupe une place de choix, surtout dans les zones frontalières, comme le montre Olga Ilyukha pour la région de la Carélie. Le discours insiste donc sur l'inviolabilité des frontières de l'URSS, imperméables aux espions et aux éléments impérialistes. Cependant, l'image du «cordon" infranchissable est bien éloignée de la réalité. Comme le montre Sabine Dullin, les frontières restent perméables, laissant par exemple passer des milliers d'immigrés illégaux vers l'URSS - pratiquants méconnus du transit inter-frontalier. Témoigne également de la fragilité de la frontière l'énorme volume des marchandises et des personnes impliquées dans la contrebande. Cette dernière est, jusqu'au début des années 1930, selon Andrey Shlyakhter, « supérieure à tout ce qu'[ait] jamais [connu] l'histoire russe, voire mondiale » (p. 406). La lutte contre la contrebande ne répond pas seulement à des objectifs économiques mais surtout, et de plus en plus, au renforcement de la sécurité d'État.

3 Par ailleurs, les régions frontalières font l'objet de politiques spécifiques. Des «zones frontalières" sont définies dès 1925 , faisant office de vitrine de la révolution à destination $\mathrm{du}$ proche étranger: elles sont le théâtre d'expérimentations et d'investissements visant à développer le socialisme. S'appuyant sur le cas de la Carélie, Nick Baron insiste sur la « centralité de la frontière » dans l'URSS en construction, c'està-dire sur l'importance de ces zones pour la définition même du régime. Cependant, parallèlement au processus de fermeture et de repli qui s'accélère dans les années 1930, la suspicion envers les éléments ennemis s'étend rapidement à l'ensemble des populations frontalières et des minorités transnationales. Nicolas Werth revient sur les étapes des répressions menées à leur encontre, qui connaissent une accélération à partir de 1935 et culminent en 1937 (déportation de l'ensemble de la minorité coréenne, opérations de nettoyage des zones frontalières). Les déplacements de populations s'accompagnent de repeuplements dont l'objectif est de façonner des régions modèles habitées d'« éléments fiables ». Les pratiques, fréquentes dans les régions frontalières, de chasse aux espions, aux saboteurs, aux éléments ennemis deviennent par ailleurs monnaie courante dans l'Union. Oleg Ken, qui analyse l'évolution du discours sur la frontière au sein des dirigeants soviétiques, montre que ce dernier tend à se propager vers l'intérieur de l'URSS. Il conclut en affirmant qu'à la fin des années 1930, « l'URSS tout entière devint une zone frontalière » (p. 334).

4 La notion et l'image de la frontière trouvent également un écho dans les opinions occidentales. Sylvain Boulouque file la métaphore de la frontière pour dépeindre la "cartographie imaginaire" qui détermine l'écosystème communiste en Europe de l'Ouest à partir de quelques exemples piochés dans les partis français et italien. En France, la lutte contre le communisme repose également sur une volonté d'établir des barrières strictes afin d'éviter la "contagion » bolchevique. Il s'agit dans un premier temps de se protéger des frontières de la jeune URSS par la création d'un «cordon sanitaire». Celui-ci repose sur des petits États-tampons, comme les États baltes par exemple, analysés par Julien Gueslin. Dans l'opinion française, ils deviennent de plus en plus associés à une ligne de démarcation perçue comme une frontière des valeurs. La rhétorique anticommuniste en France ne se contente pas de militer pour l'endiguement extérieur du communisme: elle cherche également à lutter contre les "ennemis intérieurs ». Sophie Cœuré analyse avec force cette « double frontière » présente dans le répertoire de l'anticommunisme français. Mais s'il apparaît que dans la France de l'entre- 
deux-guerres, essentiellement préoccupée par le destin de l'Allemagne, «l'anticommunisme n'eut jamais [...] la [...] fonction mobilisatrice qu'eut en URSS le discours sur l'ennemi capitaliste » (p. 61), dans les pays d'Europe centrale en revanche, les régimes des nouveaux États nés ou redessinés au début des années 1920 se construisirent en grande partie sur un discours antibolchevique. Ce dernier se mêle à une rhétorique nationaliste faisant de la Finlande (Louis Clerc), des États baltes, ou encore de la Roumanie et de la Hongrie, les derniers remparts de la civilisation et de la chrétienté face à la menace asiatique et athée que représente le bolchevisme. Soulignons ici les contributions de Florin Turcanu et de Zoltan Krasznai, qui explorent le révisionnisme des frontières en Roumanie et en Hongrie : l'idéologie antibolchevique y légitime les revendications territoriales.

5 À partir de la Seconde Guerre mondiale, la question des frontières en URSS se pose avec encore plus d'acuité. Comme le montre Mikhaïl Narinski, entre 1941 et 1946 se forge l'idée que « la sécurité de l'Union soviétique [est] liée, du point de vue du Kremlin, à son extension territoriale»(p.199). L'URSS, sortie victorieuse du conflit, conserve les territoires acquis en 1939-1941 avec le consentement de facto des Alliés. La sortie de guerre occasionne d'énormes mouvements humains. Catherine Gousseff dessine le tableau des retours de réfugiés, des rapatriements des prisonniers de guerre et des personnes internées ainsi que des transferts de population - soit autant de franchissements de la frontière soviétique, dans un sens ou dans l'autre. À compter de 1946, les flux se tarissent. Même la frontière avec la Pologne en voix de soviétisation devient hermétique (Katarina Stokolosa). Notons que la question des rapatriements n'a pas encore fait l'objet, comme le souligne C. Gousseff, de véritable analyse dans l'étude de la genèse de la guerre froide. Certains fronts actifs, comme la Transcaucasie (Taline Ter Minassian), en restent les études favorites.

6 Le point majeur dans l'évolution des frontières du communisme après la guerre concerne évidemment la création des démocraties populaires: la séparation du continent se cristallise alors autour de l'Alliance atlantique et du bloc de l'Est. Jenny Raflik et Natalia Egorova reviennent sur leur formation dans deux très bons articles de synthèse. Les auteurs soulignent l'importance accordée par chacun des camps au discours et à la propagande du camp adverse: il s'agit dès lors de tenter d'éviter des actions spectaculaires qui pourraient donner du grain à moudre aux moulins propagandistes des uns et des autres. Ces velléités n'interdisent cependant pas la consolidation des blocs. Ainsi, à l'Est, l'URSS exporte ses modes de contrôle policier des frontières (Nikita Petrov). En Pologne, les autorités soviétiques s'appuient sur des sentiments diffus dans la population - perte de confiance dans les valeurs occidentales et dans les Alliés, aura de l'URSS victorieuse, et même nationalisme panslave - afin de faire du pays un «bastion antioccidental» (Josef Laptos). Enfin, la construction du mur de Berlin vient fermer le dernier point de contact entre Est et Ouest. Bernard Ludwig donne un tableau complet des enjeux, des drames humains, mais également des problèmes pragmatiques et concrets provoqués par son érection. L'ultime passage entre deux mondes est désormais barricadé.

7 Le recueil, grâce aux synthèses générales et aux analyses régionales, offre ainsi un tableau à la fois très riche et nuancé des frontières du monde communiste en Europe. Tout en appelant à la poursuite des recherches, l'ouvrage restera incontestablement une référence incontournable pour l'étude de ces thématiques. 